\title{
Place-Names and Images of Jamaica Plain, Massachusetts
}

\author{
EUGENE GREEN
}

\section{J}

AMAICA PLAIN IS A NEIGHBORHOOD of Boston, its topographical features a diversity of park land, residential areas, and traffic patterns. ${ }^{1}$ At the borders of Jamaica Plain on the west, south, and southeast, lie Olmsted Park and its ponds, the Arnold Arboretum, and Franklin Park, all of them designed by Frederick Law Olmsted and included in the city's plan for an "Emerald Necklace," a string of parks to extend from the Boston Common to the Charles River in West Roxbury. In contrast, the areas to the north and northeast of Jamaica Plain - the neighborhoods of Mission Hill and Roxbury-contain low cost, often inadequate, public and private housing. This contrast, moreover, between open park land and subsistence housing at the borders of Jamaica Plain has had some influence upon the atmosphere within the neighborhood itself. Residences near Olmsted Park and the Arnold Arboretum are mostly single family houses, some of them more than a century old, but quite well-preserved. Yet not far away, especially within the area defined by Lamartine Street, Washington Street, and Heath Street-the area nearest Mission Hill and Roxbury-houses built originally for blue collar workers depend for their maintenance on the concern and funds invested in them by their owners. Throughout Jamaica Plain, too, one finds churches, hospitals, schools, an amateur theatre, a police station, a farm, a garden supported by the Junior League, and a museum; and on Centre Street, reminiscent in its features of a period before supermarkets and shopping malls, clusters of small stores stand close to a fire station, a post office, two libraries, and the community municipal building, the little city hall. Finally, Jamaica Plain is a corridor between downtown Boston and the suburbs. Beside Olmsted Park and the Arboretum the heavily travelled Arborway and Jamaicaway course from the city center to outlying districts; through the center of the neighborhood runs the AMTRAK system; and to the east over Washington Street rises the elevated structure of the Orange Line, part of the Boston Transit

1 This paper is a much revised version of a talk presented to the American Name Society, at its annual meeting in San Francisco, December, 1975. The research for the study, carried out during the summer of 1974, has been supported in part by a stipend from the National Endowment for the Humanities. 
System. The character of Jamaica Plain is thus heterogeneous; it includes the dwellings of the poor and the well-to-do; it supports cultural institutions and submits to the grime and din of commuter traffic.

MISSION HILL

\section{MAP 1}

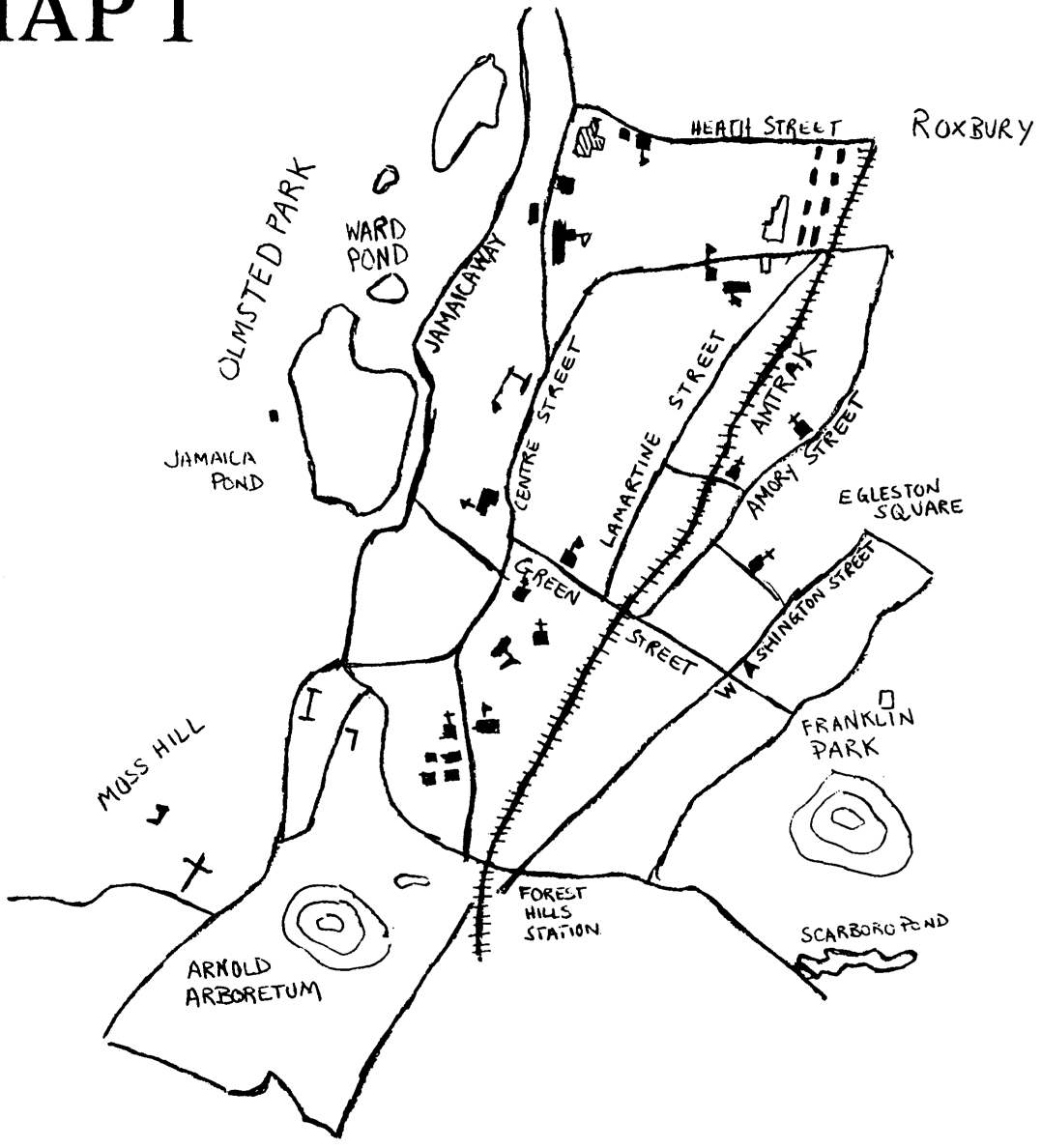

Many of the topographical features in Map 1 have their source in the maps of the United States Geographical Survey for Boston South and Newton, Massachusetts. Drawn with precision, the maps of the Geological Survey offer a reliable anatomy of particular regions like that of Jamaica Plain. Yet the disinterested approach that enables in these maps clear detail and accurate measurement must obviously exclude the sense that local residents have of their neighborhood: for example, the ways in which they perceive the topographical features in Jamaica Plain 
or the views they have of the spatial relations among those features. Surely the study of residents' perspectives, if plotted systematically, would result in a different order of map: not in a verifiable anatomy of the land, but in a variety of patterns, each the result of one's attitudes, knowledge, and experience of Jamaica Plain. Inasmuch, too, as Jamaica Plain is a heterogeneous neighborhood, it is of some value to determine to what degree, if any, residents share a common view of its topographical features and whether, despite the particular experiences of each, they none the less recognize a general outline that helps to define the community.

An inquiry into the views that residents have of a Boston neighborhood, local or downtown, is not new. Florence Ladd has contrasted the strikingly different views that black youngsters, living in Mission Hill, have of their neighborhood, whereas Kevin Lynch has been able to demonstrate that those familiar with downtown Boston share a homogeneous view of its over-all conformation. ${ }^{2}$ Moreover, in reviewing methods for determining the images that Bostonians have of the city center, Lynch has shown that a combined use of questionnaires and photographs yields excellent results. According to Lynch's findings, the more accurately one describes a section of downtown Boston, the more readily one recognizes photographs of it. The ability of respondents to identify and arrange photographs of the city center into cohesive patterns correlates well with the accuracy of their verbal descriptions.

Such a correspondence between the verbal reports of Bostonians and their arrangements of photographs surely encourages the possibility of determining whether residents also share common views of other, perhaps less well-defined, neighborhoods in the city. Moreover, it prompts questions about the structure of these images, the ways in which the features described or identified in a neighborhood interact in forming one's visual sense of it. Thus, if it is apparent that the topographical features that a resident names enter into his images of his neighborhood, it is not at all clear how the places identified help to form his images. At least three possibilities present themselves: (1) that knowing the names of topographical features is of secondary importance for shaping an image of a neighborhood; (2) that, conversely, a knowledge of these names has an overriding effect upon the shape of images; or (3), and what is most likely the case, that a knowledge of names has some importance in shaping images, but must be weighed together with other factors. Moreover, these three possibilities each imply different images of a neighborhood. Should the places identified merely have ancillary

${ }^{2}$ An account of Florence Ladd's work appears in Peter Gould and Rodney White, Mental Maps (Baltimore: Penguin, 1974), pp. 31-34. Kevin Lynch's The Image of the City (Cambridge, Mass.: The Technology Press, 1960), pp. 140-147, presents a detailed account of his methods. 
value, then the likelihood is that a resident's image of his neighborhood relies for its formation on some other criterion, perhaps on his sense of how primary and secondary streets intersect. Secondly, if the places identified are a dominant factor in forming an image of a neighborhood, then the structure of that image will in all probability reveal a rather idiosyncratic design. Thus, if two residents in Jamaica Plain each can name, for example, the same 30 topographical features, yet differ somewhat in their sense of how these features associate with one another, then their maps of the neighborhood may differ noticeably from each other. The third possibility is essentially a composite of the first two; in effect, it suggests that residents may shape images of a neighborhood, partly with the use of arbitrary dividers, such as principal thoroughfares or secondary streets, and partly with the associations that they draw among the features named. Thus maps composed from such a standpoint could well show both the influence of boundaries and the associations formed among particular places.

Finally, these different ways of forming images of a neighborhood certainly offer some possibility of constructing a composite map derived from the separate images of each resident. In attempting to draw such a composite map, one has to determine the degree to which residents share similar views of how topographical features relate to one another.

The method used in this study for investigating these possibilities owes much to Lynch's techniques for interviewing Bostonians. The photographs presented to residents of Jamaica Plain, however, differ in focus from those used by Lynch. Instead of expansive views, for example, of Commonwealth Avenue, the Charles River, or the Boston Common, photographs of Jamaica Plain each center on a particular place: a building, a pond, a section of a street. These photographs have a dual purpose: to have residents of Jamaica Plain name as many of the topographical features in their neighborhood as they can and to have them subdivide the photographs identified into separate groups, each group to contain those photographs which in their view picture places located near to one another.

Sixteen residents (11 women and five men) participated in the study. Thirteen of them are active in community affairs; two of the men worked at a local brewery for many years before it closed in 1962; one retired woman, living to herself, raised her children in Jamaica Plain. All have lived in Jamaica Plain at least 12 years, and they range in age from 20 to 81 (the mean age is 54.5; standard deviation 19.5). Their places of residence represent a broad cross section of Jamaica Plain, from the low cost public housing units at Bromley Heath in the northeastern section of the neighborhood to the upper-middle income houses to the southwest. Most have a high school education and some additional work in college 
or in technical school; one had completed the eighth grade; three have college degrees.

The materials for the study included 93 four-by-six colored photographs of separate topographical features in Jamaica Plain. The features chosen were among those mentioned in local histories, in the volumes of the neighborhood newspaper, or were related to recent events such as the taking of land for constructing a section of an interstate highway. No photograph had in it the name of the place pictured. (The Appendix lists the features photographed.) The photographs appeared in random order, each to a separate right-hand page in an album, mounted with the use of corners for the purpose of easy removal. Each had a number posted on its back for coding and tabulating.

The procedure for using the photographs during an interview consisted of the following steps. First, each resident examined the photographs in the album one after another, naming the features he knew and commenting on them as he saw fit. The second step involved the removing of correctly named photographs from the album (a step carried out simultaneously with the first) and placing them in a single pile. The third step required the rearrangement of the photographs identified into smaller groups. No resident had any difficulty with the instruction "to sort the pictures into different piles so that each pile contains the pictures of places located fairly close to one another." Finally, the number posted at the back of each photograph served as an aid for recording the various arrangements of topographical features.

The residents differed considerably in their familiarity with the neighborhood, and their ability to name the topographical features presented in the photographs varied markedly. Their success in naming topographical features ranged from as few as 25 to as many as 89 identifications; the mean for the group of residents was 57.6, and the standard deviation was 21.6. The two oldest residents and the two women living at Bromley Heath named the fewest features (their range was from 25 to 36). Misnamings occurred much less frequently: six residents had no errors, and only one resident, active in the local historical society, had more than 20 (the mean was 6.3; the standard deviation was 6.8).

The mean number of identifications for the topographical features presented was 9.5 (standard deviation 3.5). Table 1 presents the range

TABLE 1. RANGE AND PERCENTAGE OF CORRECTLY NAMED PLACES.

Range

Places Named

Percent of Total
$6-10$

30

32.3
11-13
14-16

20.4 
and percentage of identifications. In contributing to this distribution of places correctly named, the residents differed significantly in the proportion of most familiar and least familiar places they knew $\left(X^{2}=42.96 ; d f=15 ; p<.005\right)$. Those who knew the fewest of the relatively unfamiliar places (in the range of 2-10 in Table 1) also had the greatest difficulty in naming places as a whole (the four residents mentioned above). On the other hand, the two residents who named more than 80 places also identified a significantly larger proportion of the unfamiliar places than the ten residents closer to the average performance of the group, those who had correctly named from 52 to 78 topographical features $(t=10.4 ; d f=10 ; p<.005)$.

\section{MAP 2 FAMILIARITY OF PLACES}

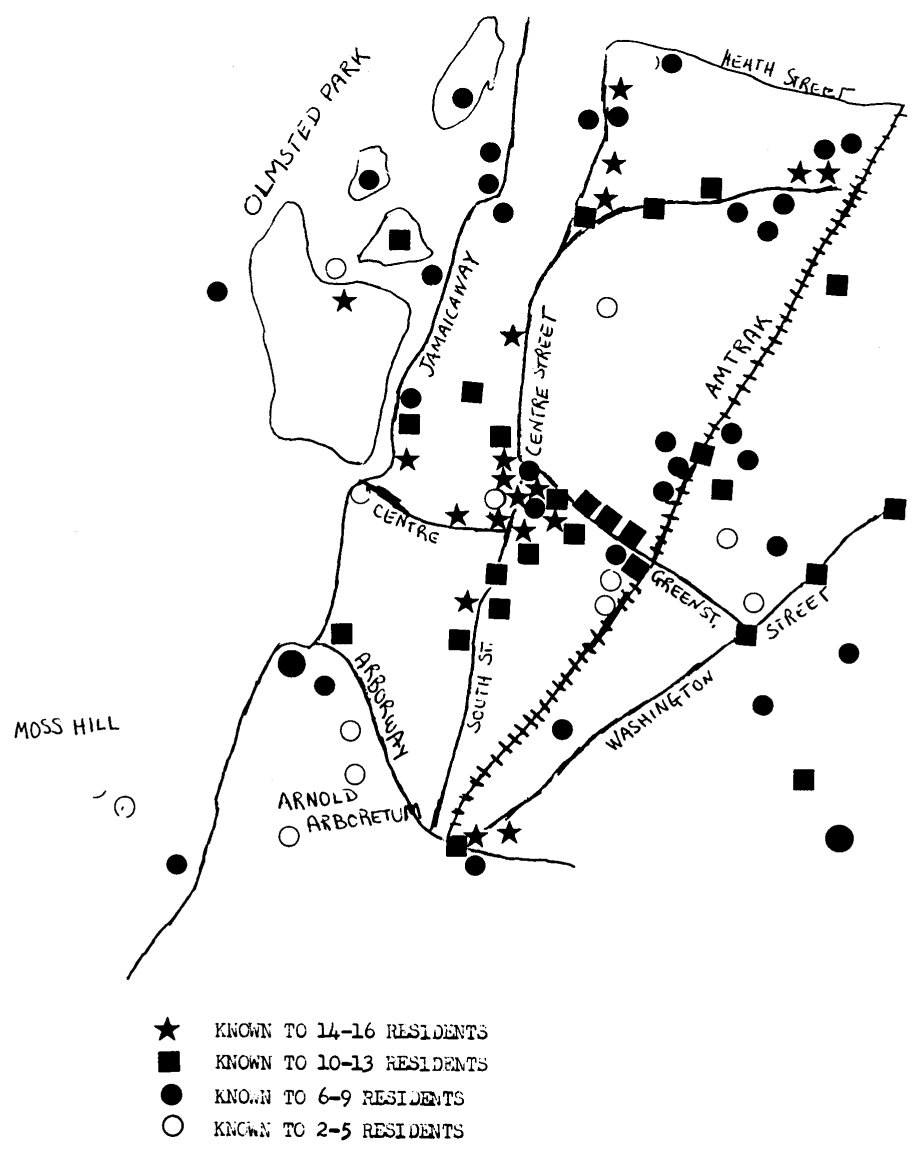


Map 2 charts the facts of Table 1. Quite plainly, nearly half the least familiar places appear south and west of the Arborway, in the Arnold Arboretum and in the Moss Hill region of Jamaica Plain. Many of the familiar places, in contrast, occur in the main business district of the neighborhood, on Centre Street south of Green Street. The types of topographic feature, however, have no significant bearing on the residents' performance. Although places used for cultivation (see the Appendix) were the most difficult to recognize and to identify, they did not prove significantly harder to name than the feature second in difficulty for the residents - the outdoor wall murals scattered east of Centre Street, along the railroad embankment, and in the Bromley Heath housing project $(t=1.6 ; d f=7 ; p>.05)$. Thus no simple explanation accounts for what makes a topographical feature easy or difficult to identify. At best, the location of topographical features in the area of Jamaica Plain has some effect on the ability of residents to name them.

Just as the residents varied widely in their ability to name topographical features, so they differed in the ways that they subdivided photographs into separate groups. The number of subdivisions that they made ranged from two groups of photographs for one resident who lives at Bromley Heath to 33 groups for the resident who named the most features (the mean number of sub-divisions was 11.7). Moreover, there was no significant correlation between the number of features identified and the number of groups into which residents sorted them. Furthermore, the residents hardly agreed on the number of topographical features which they assigned to the subdivisions they had made. One subdivision, for example, contained 44 photographs, whereas 40 subdivisions had only one. Table 2 presents the frequencies with which photographs appeared in the various subdivisions. Again, there is no correlation between the number of topographical features identified by each resident and the number of photographs which each placed, on the average, in particular subdivisions.

TABLE 2. FREQUENCY WITH WHICH VARIOUS SUBDIVISIONS OF PHOTOGRAPHS APPEARED 
The mean number of photographs in a subdivision, 4.9, was used together with the standard deviation, 5.7, to arrange Table 2 into three groups: the subdivisions containing from one to four photographs fall below the mean; the subdivisions containing from five to nine photographs fall between the limits of the mean and the first standard deviation; and the subdivisions containing ten or more photographs (except for the four groups of ten photographs) occur beyond the limit of the first standard deviation.

The marked differences among the residents in their ability to name topographical features and in the ways they grouped photographs together suggest as well considerable variations in their images of Jamaica Plain. The very contrast in the number of photographs assigned to the subdivisions argues that residents hardly share a unified view of the neighborhood. Map 3 with its 16 sketches (one for each resident) tries to capture the divergence in points of view. The sketches each include a drawing of the Jamaicaway, Centre Street, and Washington Street. Some of the sketches, too, depict the AMTRAK system and indicate the names of such secondary streets as South Street, Green Street, Boylston Street, South Huntington Avenue, Perkins Street, and Heath Street. A filled circle denotes where a resident either works or lives. In addition, subdivisions within the sketches have three different forms; those with ten or more photographs are designated by a number (see Sketch I); those containing from five to nine photographs are marked by hatches (as in Sketch VI); and those with four or fewer photographs appear with points and connecting lines (see Sketch III). This pattern of marking subdivisions into three different zones corresponds with the results listed in Table 2.

Two assumptions govern the way that zones are laid out in the sketches. The first assumption is that in arranging topographic features of Jamaica Plain into separate groups, the residents were in effect identifying particular zones or areas. The second assumption is that each subdivision of topographical features includes the area near and about them. If two ponds, for example, appear in a subdivision, then the land connecting them is also included. Likewise, if a resident grouped together several buildings located within the perimeter formed by several streets, then those streets and all the land within them also belong to the same subdivision.

Now a review of the sketches helps to identify some of the criteria that helped to form the images that residents have of Jamaica Plain. The first five sketches include large zones composed of at least ten topographical features. For each of these zones, primary and secondary streets help to mark the borders between them. Sketch I of three zones (comprising 72 topographical features) has clearly marked borders at the Jamaicaway 

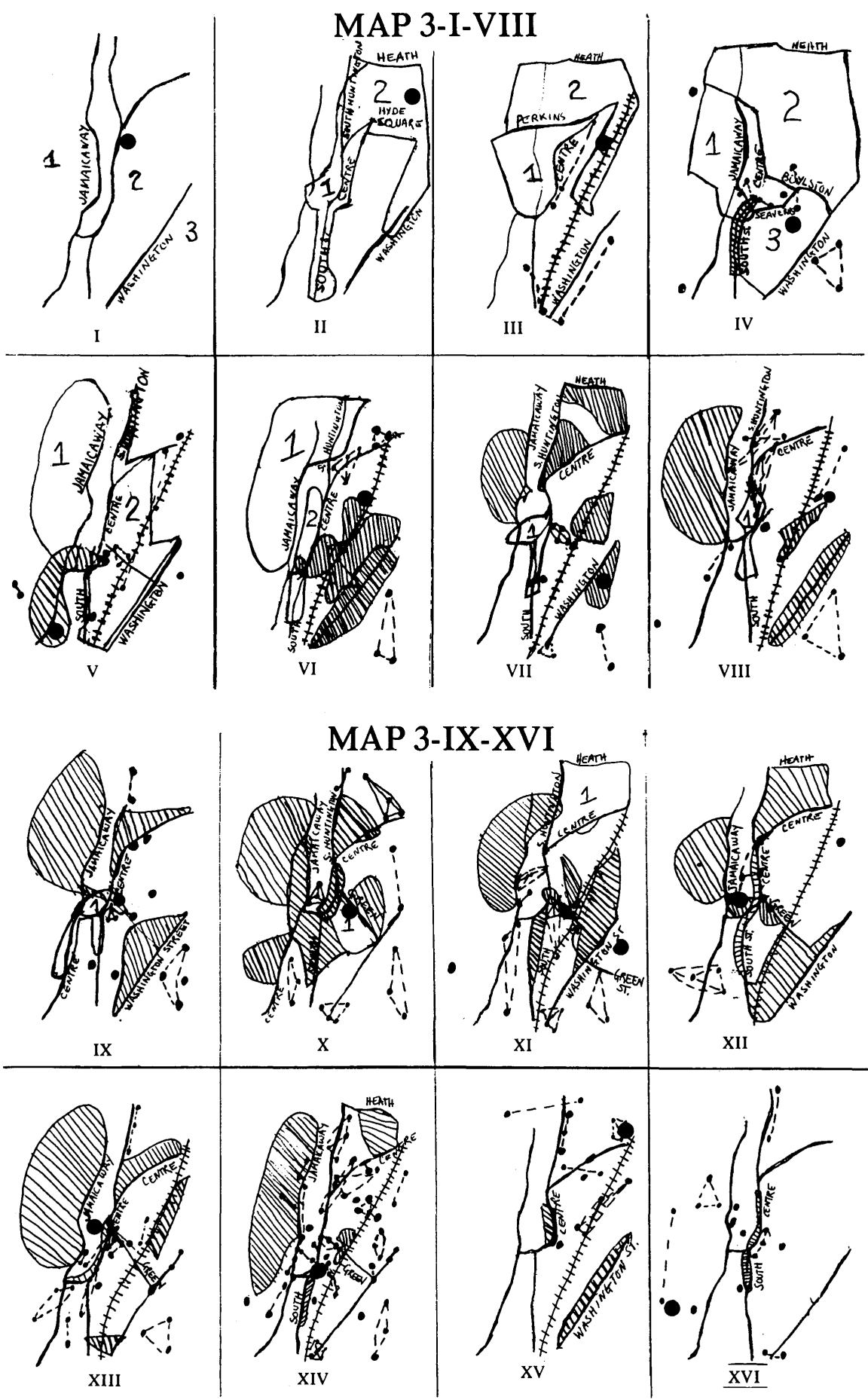
and at Washington Street. The jagged and truncated zones in Sketches II and III are largely the result of the ways in which the two residents (one of them dwelling at Bromley Heath; the other 80 years old) combined the relatively few topographical features (34 in Sketch II; 35 in Sketch III) they could identify. In Sketch III, too, the three points connected to one another just east of Centre Street designate the Jamaica Plain High School and two grade schools, one of the very few instances in which the type of topographical feature influenced a resident's sorting. Moreover, in Sketches II and III (as well as in Sketches XV and XVI) the features identified are mainly those nearest to a resident's home; these are the sketches of residents living at Bromley Heath or those older than 80 .

Sketch IV is based on 81 topographical features. The three numbered zones are compact and bordered by main thoroughfares and secondary streets. At the center of the sketch, in an area somewhat like a "buffer" among the three numbered zones, the resident has clustered three groups of topographical features, three or fewer features in each zone. Note also that the one zone marked with hatches extends along South Street, across Zone 1 and into the same "buffer" area. Sketch V of 59 topographical features also illustrates the overlapping of zones. The zone marked with hatches crosses Zones 1 and 2; the resident referred to the zone with hatch marks as the one which she knew intimately; her house is located in its midst.

Sketches VI through XII also include numbered zones (all but XII), but the incidence of zones marked with hatches is predominant. What characterizes these hatch-marked zones is that some of them have either one or two borders near a main thoroughfare or near the AMTRAK system, or else a thoroughfare or the railroad runs through them as a kind of spine. In most of the sketches (VI, IX, X, XI and XII), the zones once again overlap. Moreover, most residents as in Sketches VI, VII, X, XI and XII divide particular streets or the railroad track into sections, each section serving as a border or a center for a particular zone. The number of topographical features identified in this group of sketches ranges from 52 to 78, a range fairly close to the over-all mean of 57.6. Within this group of sketches, too, the zones depicted apply by and large to all areas of Jamaica Plain. Only in Sketches VI and VII does the evidence suggest some unfamiliarity with the southwest corner of the neighborhood, whereas Sketch XII omits points to the east.

Finally Sketches XIII through XVI comprise zones consisting mainly of four or fewer topographical features. Thoroughfares and the railroad have a diminshed rôle, yet the points connected to one another are fairly close. Even in these sketches zones overlap, especially near Centre Street as in Sketches XIII and XIV. In all, the topographical features identified 
in this last group of sketches take precedence over bordering streets in influencing the residents in their forming of subdivisions. If Sketches XV and XVI contain few features, Sketch XIII includes 76 and Sketch XIV 89.

Throughout these sketches, then, several criteria exercise some influence on the residents' arrangements of photographs. Surely, most residents are guided by the relation of topographical features to main thoroughfares, to secondary streets, and to the railroad. Also, some areas such as Olmsted Park west of the Jamaicaway and Franklin Park east of Washington Street form self-contained units. In a number of sketches, too, a thoroughfare or the railroad may serve as a border or center for more than one zone. In a few sketches, on the other hand, most emphasis is placed on the immediate association among a few topographical features (primarily in Sketches XIII and XIV). Finally, the arrangement of zones within the sketches, insofar as they overlap, indicates that residents do not always regard space as contiguous, that the associations they draw among topographical features may not always accord with actual, spatial lay-outs. Especially near the borders of zones, near Centre and Green Streets, does one find "fuzzy" borders.

In effect, the residents draw upon a few criteria to arrange topographical features, yet the use of these criteria may well result, as in the 16 sketches of Map 3, in rather idiosyncratic configurations. At first glance, indeed, the disparity among the sketches offers little hope for determining a coherent structure to which they might all be related. Nevertheless, an analysis of these sketches does reveal that for all their diversity they share in a common, underlying structure. The analysis consists of the following steps. First, all the topographical features placed together in a zone were paired with one another. Thus, if in one zone, the church of St. Thomas Aquinas, Agassiz School, a section of South Street, and the Sedgwick Street Library appear together, then it is possible to combine these features into six different pairs. The total number of paired features in the zones formed by the residents is 1952 . The second step in the analysis is to determine the rate at which any two topographical features identified by the residents appear together as pairs. The equation used to determine the rate of agreement for a pair of topographical features is this:

Rate of agreement for a pair of topographical features

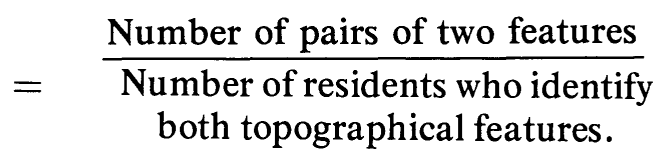


For example, of the ten residents who identified both the church of St. Thomas Aquinas and a section of South Street, eight paired them together in a zone for a .8 rate of agreement. Of those 12 residents who identified St. Thomas Aquinas and Agassiz School, six paired them together for a .5 rate of agreement. Most rates of agreement, however, are far lower, and Table 3 summarizes the results for all 1952 pairs.

TABLE 3. RATE OF AGREEMENT FOR PAIRED PHOTOGRAPHS.

$\begin{array}{lrrr}\text { Rate of Agreement } & .07-.28 & .30-50 & .54 \text { to } 1.00 \\ \text { Number of Pairs } & 1281 & 417 & 256 \\ \text { Percentage of Pairs } & 66 & 21 & 13\end{array}$

Mean $=.28 ;$ Standard Deviation $=.23$

What is quite clear from the results listed in Table 3 is that only 13 percent of all the paired topographical features exceed a rate of 50 percent agreement, a rate that extends beyond the limit of the mean and the first standard deviation. By far, most pairs show the idiosyncratic choices of the residents, 65 percent falling below the mean of .28 .

Yet if one composes a map of the topographical features paired together at a rate of .54 or greater (the upper 13 percent of paired features in Table 3), the result is a coherent structure. Map 4 presents eight zones within Jamaica Plain: (1) Olmsted Park and the Jamaicaway (filled squares); (2) Arnold Arboretum and Moss Hill (blank circles); (3) Centre and South Streets (filled circles); (4) Centre Street, South Huntington Avenue, and Heath Street (open squares); (5) Lamartine Street and eastward toward Washington Street (filled stars); (6) Green Street southward near the AMTRAK system (open circles); (7) Washington Street (filled circles); (8) Franklin Park (open circles).

The name of each numbered point on the map appears in the Appendix (all 93 topographical features in the study occur in one zone or another). That topographic features occur together in a zone does not mean, however, that all of them were paired to one another at a rate of at least .54 (see Table 3). Within a particular zone, e.g., Zone 4, the number of pairings among the 21 topographical features joined together ranged from one to 11 . Thus only in one instance did point 92 enter into a pairing with another point that exceeded a rate of .54 ( 92 is joined to 17 at a rate of .55). On the other hand, point 17 also entered into pairings with points 63 and 66 . In effect, the method for determining topographical features in a zone is to link points together in a kind of chain, each feature linked to as many others as possible. Only one pair of all 


\section{MAP 4}

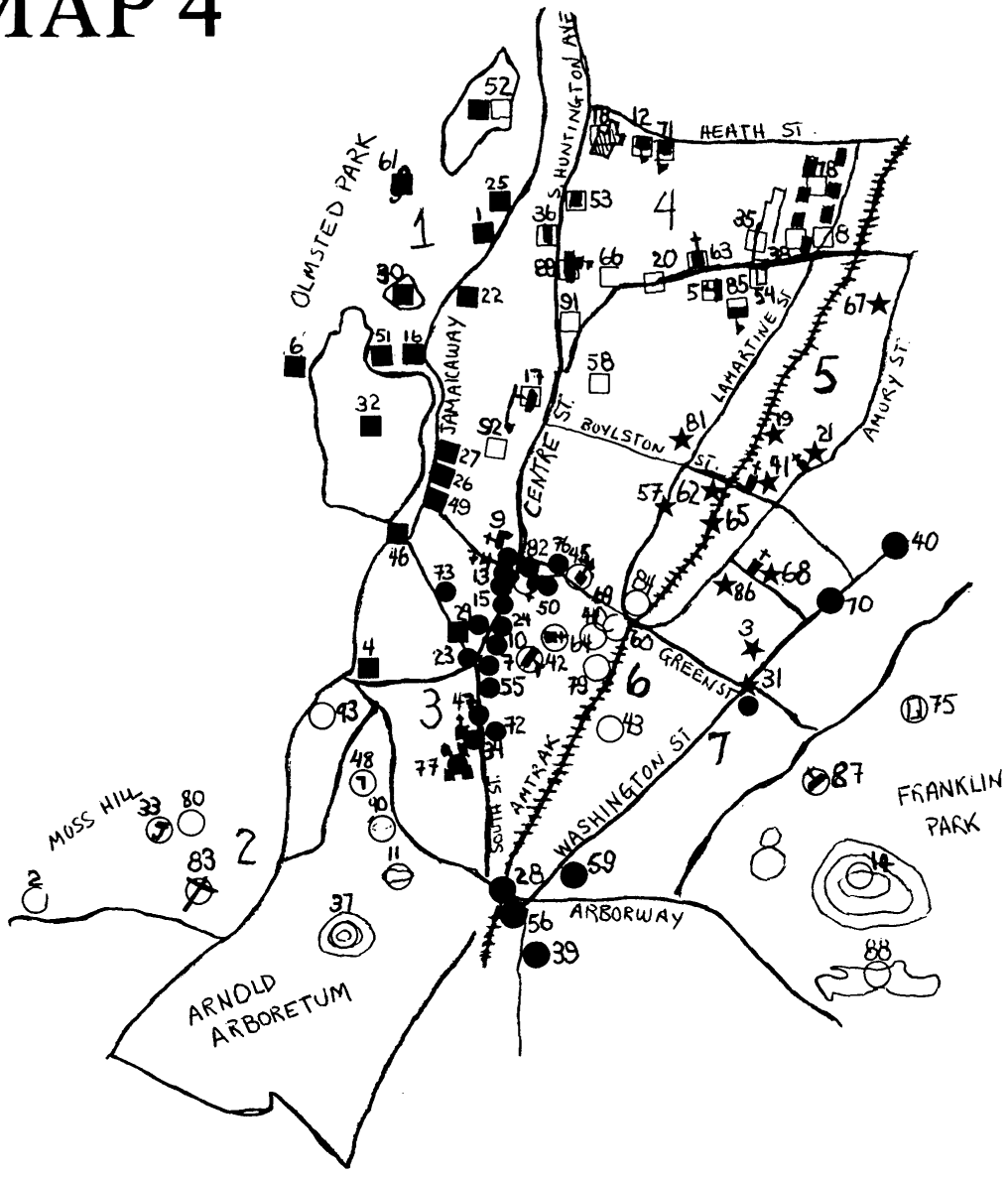

those that fell within the top 13 percent of Table 3 is excluded from Map 4, the link between point 11 (the Arnold Arboretum Pond) and point 52 (Leverett Pond in Olmsted Park). Otherwise, all the points in the several zones are in plausible relation to one another, all in close proximity, near the thoroughfares implicitly designated by the residents as borders or centers for their own sketches. Some points, furthermore, are members of adjacent zones: Leverett Pond, point 52, is in Zones 1 and 4; the Central Congregational Church, point 50 , is in Zones 3 and 6; the Thomas Street Parking Lot, point 29, is in Zones 1 and 3; and the Green Street Station, point 31, is in Zones 5 and 7.

Map 4 also indicates that the number of topographical features in the eight zones ranges from four in Franklin Park, Zone 8, to 21 in Zone 4. Moreover, throughout the several zones of Map 4, the greater the number of topographical features that occur in a zone, the greater, too, 
is the number of pairings above $.54(\mathrm{r}=.88$ in a test of correlation by rank). Finally, an analysis of the residents' pairings of topographical features indicates that the more each of them could identify places pictured in the photographs, the more each contributed to establish the paired features that enter into Map $4(r=.90$ in a test of correlation by rank). All told, Map 4 implies that those who can best identify places in Jamaica Plain also have a fuller sense of how these places are related to one another.

To some degree, Map 4 has a familial relation to the 16 sketches of Map 3. The resemblance among all the depictions of Jamaica Plain is very much like that one sees among parents and siblings. None of the sketches in Map 3, nor Map 4 itself, can count as the essential image; instead one must respect the interplay between idiosyncratic associations and features held in common. Even a thorough account of Jamaica Plain topographical history rests on the preferences of the historian. In none of the interviews did residents consistently comment on the places identified, nor did any explain except for a phrase or two why it was that he arranged the topographical features into particular subdivisions. Fortunately, however, one member of the Jamaica Plain Historical Society, a student at Harvard, has indeed traced the history of her neighborhood and has drawn a map to explain her division of its topographical features into seven zones. Map 5 is based on the work of Mrs. Cynthia Zaitzevsky. $^{3}$

Mrs. Zaitzevsky's map, if compared to Map 4, again shows the qualities of a familial likeness. If in Map 4 the areas near Olmsted Park and the Arnold Arboretum divide into two zones, Mrs. Zaitzevsky chooses to regard them as one, for in her view, these areas are "hilly and still country-like in many places." Mrs. Zaitzevsky also combines Washington Street and the land eastward toward Franklin Park (Zones 7 and 8 in Map 4), yet she notes that the "severely deteriorated state of the commercial strip along Washington Street" differs markedly from "the many spacious shingle-style and Colonial revival houses" near Franklin Park. Perhaps the strongest contrast between Maps 4 and 5 is due to Mrs. Zaitzevsky's displeasure with Centre and South Streets. She does not recognize the two streets as an integral zone, for she regards them as "an undistinguished and traffic-choked commercial strip." On the other hand, she does say that Centre Street forms a "natural topographic boundary" between the land to the west (close to Olmsted Park),.which is flat with straight streets, and the land eastward toward the AMTRAK right-of-way, which "is steep with a confusing street pattern." Elsewhere

${ }^{3}$ Mrs. Zaitzevsky's history appears in an unpublished monograph "Jamaica Plain Survey." I wish to thank Mrs. Zaitzevsky for permission to draw upon her work. 


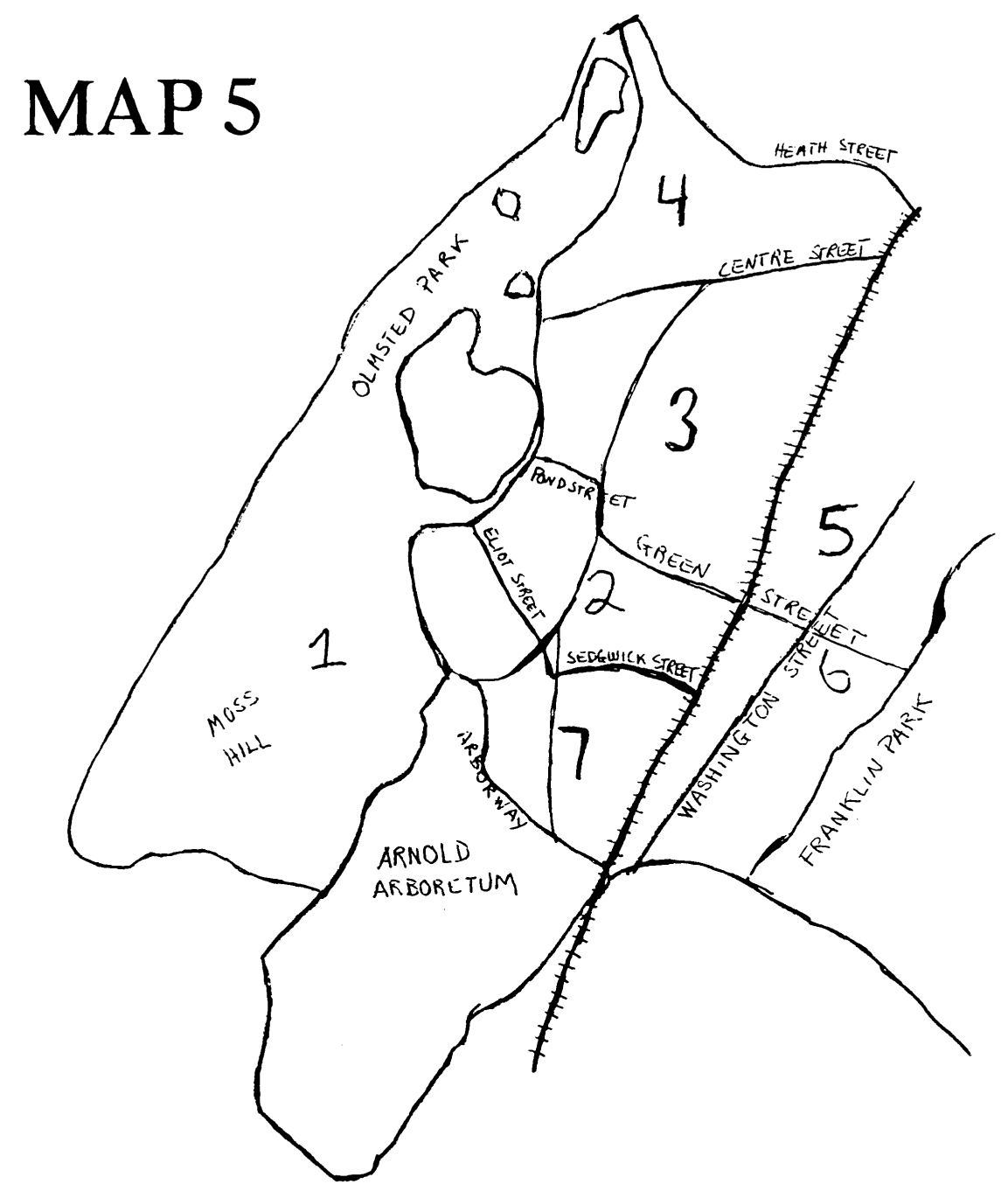

Maps 4 and 5 are quite alike, especially Zone 4 of each, located to the north of Centre Street.

Mrs. Zaitzevsky articulates an attitude shared by most of the 16 residents who participated in this study. If they did not address themselves in detail to the quality of each topographical feature, they none the less expressed a desire to preserve the aesthetically satisfying aspects of their neighborhood and to rehabilitate those areas suffering from deterioration. What they all wish is a Jamaica Plain that contributes to congenial living. Although the residents may differ in particulars and in their sense of what is in fact desirable, most of them subscribe to a 
common view that expresses itself in the familial resemblances of the sketches and maps.

The method used in this study to evoke the images of residents has a heuristic value. To be able to name the topographic features of a neighborhood serves as one index of one's familiarity with it. To group the topographical features named is also helpful. Yet the method needs to be supplemented as well by a careful investigation of residents' responses to these features and groupings. In a more detailed analysis, one could probe the strength of association that residents form among the topographical features they identify and probe, too, just what importance primary and secondary streets have in dividing a neighborhood into zones. The design of this study, then, lends itself to extension, to a fuller procedure for determining the ways that the residents of a community place themselves in relation to their surroundings.

\section{Boston University}

\section{APPENDIX}

The numbers appearing to the left of place-names correspond to the numbers posted on Map 4. The first number to the right of a place-name indicates the frequency with which it was identified. The second number to the right designates the frequency with which the topographical feature entered into pairings at a rate of .54 or greater with other features (the rate used for drawing Map 4). Classifications of topographical features appear to the far right, after the numbers related to each placename.
1. Kelley Skating Rink
2. Allendale Farm
3. Brookside Health Clinic
$8 \quad 8 \quad$ Recreation
4. Boy Scouts of America
52 Cultivation
5. Wyman School
44 Hospital and Clinic
6. Parkman Memorial
7. Curtis Hall
8. Bromley Heath Mural
131
Private Institution
$7 \quad 11$
Public School
910
Monument
9. First Baptist
Public Building
$15 \quad 7$
$6 \quad 7$
Outdoor Mural
10. Loring-Greenough House
128
Church
11. Arboretum Pond
12. Jefferson School
13. Centre Street Fire Station
14. Franklin Park Golf Course
103
55
$4 \quad 10$
$16 \quad 7$
112
15. Centre Street
16. Sugarbowl
$16 \quad 6$
$10 \quad 11$
17. Mary Curley School
$15 \quad 3$
18. Boston Veterans Administration Hosp. 
19. Haffenreffer's Brewery

20. Centre Street, North of Hyde Square

21. St. Andrew's Methodist

22. Jamaica Towers

23. Soldiers' Monument

24. Gino's

25. Daisy Field

26. Rogerson House

27. Our Lady of the Way

28. Forest Hills Overpass

29. Thomas Street Parking

30. Ward Pond

31. Green Street Station

32. Jamaica Pond

33. Manning School

34. St. Thomas Aquinas

35. Plant Shoe Factory

36. Home for Aged Women

37. Bussey Hill

38. Bromley Heath

39. Hyde Park Avenue

40. Egleston Square

41. Boylston Congregational

42. Jamaica Plain High School

43. Boston Gas

44. Elm Street Vegetable Garden

45. Bowditch School

46. Kelley Circle

47. South Street

48. Administration Building, Arnold Arboretum

49. Children's Museum

50. Central Congregational

51. Pinebank

52. Leverett Pond

53. Massachusetts Homeopathic Hospital

54. Mozart Street Playground

55. Sedgwick Street Library

56. Forest Hills Station

57. Lamartine Street

58. Embankment Garden

59. Washington Street Bus Depot

60. Woolsey Square Mural

61. Willow Pond

62. Boylston Street Mural

63. Blessed Sacrament

64. St. John's Episcopal

65. AMTRAK System

66. Hyde Square

67. Holzer-Cabot Housing

Business Concern

Street and Rail

Church

Multiple Dwelling

Monument

Business Concern

Recreation

Multiple Dwelling

Multiple Dwelling

Street and Rail

Street and Rail

Natural Feature

Street and Rail

Natural Feature

Public School

Church

Business Concern

Multiple Dwelling

Natural Feature

Multiple Dwelling

Street and Rail

Street and Rail

Church

School

Business Concern

Cultivation

Public School

Street and Rail

Street and Rail

Private Institution

Private Institution

Church

Natural Feature

Natural Feature

Hospital and Clinic

Recreation

Public Building

Street and Rail

Street and Rail

Cultivation

Street and Rail

Outdoor Mural

Natural Feature

Outdoor Mural

Church

Church

Street and Rail

Street and Rail

Multiple Dwelling 
68. Our Lady of Lourdes

69. The Green Elm

70. Washington Street

71. Hennigan School

72. Agassiz School

73. Eliot Hall

74. Jamaica Plain Post Office

75. White Stadium

76. Station 13

77. South Street Housing

78. Martha Eliot Health Center

79. Call Street APAC Mural

80. Mossbank

81. Danforth Street Schulverein

82. Hailer's Pharmacy Mural

83. Faulkner Hospital

84. Johnson Playground

85. Kennedy School

86. APAC Neighborhood House

87. Ukrainian Orthodox Church

88. Scarboro Pond

89. Cardinal O'Connell Seminary

90. Wisteria Arbor

91. Connolly Library

92. Pond Street Housing

93. Monastery of the Poor Clares $\begin{array}{lll}88 & 8 & \text { Church }\end{array}$

87 Business Concern

121 Street and Rail

89 Public School

132 Public School

142 Private Institution

164 Public Building

83 Recreation

101 Public Building

107 Multiple Dwelling

65 Hospital and Clinic

46 Outdoor Mural

23 Street and Rail

622 Private Institution

$\begin{array}{lll}8 & 2 & \text { Outdoor Mural }\end{array}$

83 Hospital and Clinic

116 Recreation

$810 \quad$ Public School

53 Private Institution

81 Church

822 Natural Feature

152 Private Institution

33 Cultivation

128 Public Building

121 Multiple Dwelling

82 Multiple Dwelling

\section{NECROLOGY}

The Secretary-Treasurer regretfully announces the death of Professor Ralph B. Long on January 25, 1976. 